\title{
IN-SERVICE AND PRE-SERVICE SPECIAL EDUCATION TEACHERS' PERCEPTION OF NCTM STANDARDS: IMPLICATIONS FOR PROFESSIONAL DEVELOPMENT
}

\author{
Emad M. Alghazo ${ }^{1+}$ \\ Yazan M. Alghazo ${ }^{2}$
}

\author{
'Associate Professor, Special Education Program, Al Ain University United \\ Arab Emirates. \\ Email:emad1171@gmail.com Tel:00971502783415 \\ -Assistant Professor, Mathematics Education Bahrain Teacher College \\ University of Bahrain, Bahrain. \\ Email:yalghazo@uob.edu.bh Tel:0097317437427
}

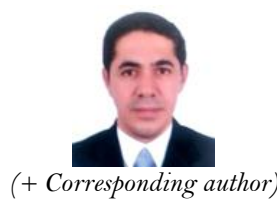

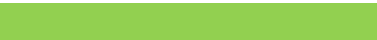

Article History

Received: 7 August 2020 Revised: 16 September 2020 Accepted: 2 October 2020 Published: 14 October 2020

\section{Keywords}

Learning disabilities Mathematics NCTM standards Perceptions

Professional development Special education teachers.

\begin{abstract}
Special Education teachers face increasing difficulties when teaching students with Mathematical learning disorders. The purpose of this study was to investigate whether special education pre-service and in-service teachers in a university in the Middle East are receiving proper training to deal with students with disabilities in learning mathematics. A 24-item self-developed questionnaire was distributed to a sample of 95 $(\mathrm{N}=95)$ special education pre-service and in-service teachers. The analysis of the data revealed that pre-service teachers had not accomplished sufficient competency in any of the NCTM standards that are necessary for providing meaningful and useful learning experiences to their future students. However, the analysis of the data revealed that inservice teachers had sufficient competencies in all NCTM standards. These results help to contribute in informing the design and implementation of teacher education programs. Implications of these findings are further discussed along with recommendations for further development within the teacher education program for special education teachers.
\end{abstract}

Contribution/Originality: The study documents the current levels of understanding of the NCTM standards among Middle Eastern special education pre-service and in-service teachers. Furthermore, the study draws attention to the needs for professional development programs that adequately prepare special education teachers for teaching mathematics to students with learning disabilities.

\section{INTRODUCTION}

A growing body of research has produced significant findings about the characteristics of mathematics learning disabilities, assessment, and mathematics programming. For instance, investigations have shown that students may exhibit difficulties using effective cognitive and metacognitive problem-solving strategies (Montague \& Applegate, 1993) memory and retrieval processes (Bley \& Thornton, 1995) and generalization skills (Woodward, 1991) which stem from developmental delays (Cawley. \& Miller, 1989) and cognitive deficits. These difficulties manifest themselves in the inability to acquire and apply mathematical skills and concepts, to reason, and to solve mathematical problems. The resulting poor mathematics performance (ranging from mild to severe) in traditional curricula impedes students' abilities to compete with their typical peers (Cawley et al., 1992). Varying levels of support are needed to accommodate individual student needs, which in some cases mean intensive, individualized special education instruction. Preparing teachers with the ability to select worthwhile tasks that support student learning is not always the only way to improve their instructional outcomes (Boston \& Smith, 2009). It is also 
important to provide support for teachers in dealing with students with different levels and different abilities in mathematics (National Council of Teachers of Mathematics (NCTM), 2007).

Special educators around the world face many challenges. One of the biggest challenges that special education teachers encounter in schools deals with students who have mathematic learning disabilities. There is an estimate of about $6 \%$ of the general population that have some type of arithmetic disability (Badian, 1983). It is also estimated that about one-fourth of students who have learning disabilities have some type of deficiency in mathematics (Brian, Bay, Lopez-Reyna, \& Donahue, 1991).

In general, students with learning disabilities also have substantial problems with mathematics (Scheid, 1990). While Mathematics learning disabilities are not widely reported, their prevalence is estimated to be between five and eight percent (Desoete, 2007; Geary, 2004; Stock, Desoete, \& Roeyers, 2006; Van Steenbrugge, Valcke, \& Desoete, 2010) (McLeod \& Armstrong, 1982) surveyed teachers who were teaching students with learning disabilities; the teachers reported that $26 \%$ of their students received services due to mathematical problems in general education classroom (McLeod \& Armstrong, 1982). Mathematics learning disabilities, as noted by researchers, are apparent throughout the school years, but they tend to stabilize at the fifth- or sixth-grade level (Cawley, Baker-Kroczynski, \& Urban, 1992; Cawley. \& Miller, 1989).

Researchers have identified specific deficiencies in mathematics, mainly in the areas of computation and word problems. Retrieval of facts, for example, is one of the deficits that students exhibit in the area of computation retrieval (Garnett \& Fleischner, 1983). Another example is the speed of processing and problem conceptualization (Geary, 1993). Also, students are unable to use calculation strategies effectively (Geary, 1990; Goldman, Pellegrino, \& Mertz, 1988).

Students in both regular education and special education suffer from solving word problems, but it is more evident for students who have mathematics learning disabilities. Researches have linked the difficulties students have with solving word problems to various aspects, such as the complexity of structure; complexity of semantics; deficiencies in both cognitive and metacognitive skills; lacking computational skills; and the difficulty with multiple steps (Englert, Culatta, \& Horn, 1987; Parmar, 1992; Parmar, Cawley, \& Frazita, 1996).

Recently, with the increase of implementation of inclusive classrooms, mathematics teachers and special education teachers are being forced to deal with very similar issues when it comes to teaching mathematics (Sheppard \& Wieman, 2020). However, recent studies have shown that special educators and mathematics educators differ significantly in their levels of preparation and in dealing with students with special needs. They also differ in their perception about the importance of knowledge of individual student needs (Sheppard \& Wieman, 2020).

In response to these chronic mathematical difficulties, special education researchers have identified critical instructional and curricular variables that promote effective programming for students with mathematics learning disabilities (Cawley \& Parmar, 1992; Mercer \& Miller, 1992; Rivera \& Smith, 1987). Drawing from cognitive and developmental psychology and behavioral theory, the knowledge base of what constitutes sensible instructional practices for youngsters with math LD has increased significantly in recent years. For instance, researchers have identified discrete instructional design variables, such as explicit strategies (Fuchs, Fuchs, Hamlett, \& Appleton, 2002; Kelly, Gersten, \& Carnine, 1990; Montague \& Bos, 1986) relevant practice and alternative algorithms (Cawley \& Parmar, 1992) that foster mathematical understanding and evaluative thinking and promote a better match between learners with math difficulties and the skills and concepts presented for instruction.

A large body of research has investigated the best practices and teaching strategies that might best serve a student population that includes students with mild to severe learning disabilities in mathematics (Spooner, Root, Saunders, \& Browder, 2019). For example, in their comprehensive review of the literature on best practices for teaching mathematics to students with learning disabilities, Spooner et al. (2019) concluded that systematic instruction, technology-aided instruction, and explicit instruction are considered evidence-based practices that best 
serve a population of students with learning disabilities in mathematics. Similarly, Jimenez and Stanger (2017) identified the use of virtual manipulatives as an evidence-based strategy that best serves students with disabilities.

To assist teacher educators in identifying necessary competencies for future teachers, the Council for Exceptional Children issued a special education competency list, and the Division for Learning Disabilities (DLD) published their DLD Competencies for Teachers of Students with Learning Disabilities (Graves et al., 1992). The conceptual basis of the DLD competencies includes general education preparation, a knowledge-based dimension, a service delivery dimension, and competency categories consisting of 209 competencies and clinical field experience. Mathematics falls within the "Specialized Instructional Strategies, Technologies, and Materials" category and contains 12 competencies covering topics such as curricula, instructional techniques, remedial techniques, readiness, developmental teaching progressions, mathematics programming, and research.

Cawley and Parmar (1992) present a vital discussion regarding issues about and techniques for preparing teachers to teach mathematics to students with learning disabilities. They use the Professional Standards for Teaching Mathematics (National Council of Teachers of Mathematics, 1991) and the DLD competencies to frame their case for examining current preparation practices and changing the way we prepare our future special education teachers. Of critical importance is whether teachers are being prepared to challenge their students mathematically (i.e., incorporate the Standards into teaching), to teach their students important mathematical life skills, and to use instructional techniques that deviate from the more traditional paper-and-pencil, rotememorization instruction.

The DLD also issued a document referred to as Knowledge and Skills Competencies for teachers of students with disabilities. The document emphasizes that teachers must be familiar with the curriculum, instruction, and assessment in mathematics (Graves, Landers, Lokerson, Luchow, \& Horvath, 1993). Yet, recent studies have shown that teachers who teach students with severe to moderate developmental disabilities feel that they lack the needed skills and competencies to address the needs of their students sufficiently (Lee, Browder, Flowers, \& Wakeman, 2016) which further supports the need to provide teachers in inclusive classrooms with the needed training to deal with students with mathematics learning disabilities.

Cawley and Parmar (1992) emphasized the importance of modeling good mathematics teaching in university course work through hands-on problem-solving activities. They stressed the need for teachers to have a sound knowledge base in mathematics, including breadth and depth in curriculum and instruction. They reminded how crucial it is for future teachers to understand their students' specific mathematical difficulties. Such awareness enabled them to plan effective mathematics programs and to be well-grounded in mathematics pedagogy. Cawley and Parmar (1992) acknowledged that an individual requires time to develop as a "teacher of mathematics" and that he or she should become familiar with different theoretical orientations to the teaching and learning of mathematics.

The field of mathematics special education has experienced significant growth in response to an increased awareness of the prevalence of mathematics learning disabilities (LD) and the pervasive and persistent nature of the ensuing difficulties across the elementary and secondary school curricula (Cawley \& Miller, 1989; Garnett, 1987). Furthermore, results from follow-up and follow-along studies indicate that individuals with mathematics learning disabilities tend not to perform at a level commensurate with their peers' on the basic functional skills (e.g., telling time, counting change) that are necessary for successful adult living (Jordan, Glutting, \& Ramineni, 2010; Lyons \& Beilock, 2011; Wagner, 1990).

However, researchers have identified over the years, a big gap between research and practice, it is, therefore, crucial that Programs at the university level prepare educators to be able to meet the needs of all students, including students with disabilities. While many researchers have identified the needed competencies and knowledge required by special educators in dealing with students with deficiencies in mathematics, few research studies investigate the degree in which these competencies are introduced at the teacher education level. 
Therefore, teachers should be aware of the instructional techniques, knowledge, and the understanding of mathematical concepts to be able to assist students with mathematical problems. Teachers should be aware of individual differences among students and be able to individualize instruction based on each student's level of functioning.

Teacher education programs must evaluate the extent to which they are preparing teachers to meet students' unique needs so that students with learning disabilities can successfully complete the school curriculum and effectively utilize mathematics in other subject areas and in activities of daily living.

The purpose of the current study was to find out whether special education pre-service teachers in their last semester at an Arab University had the training needed to teach mathematics to students with disabilities. More specifically, the study aims to explore the different competencies among pre-service and in-service teachers based on the NCTM standards that enable those teachers to be better prepared in dealing with students with special needs.

\section{METHOD}

Participants: The study utilized a quantitative research design. The questionnaire was distributed to 60 preservice teachers and 70 in-service teachers, and included with the questionnaire was a letter inviting them to participate in the study, and that anonymity will be guaranteed for all participants. out of the 60 questionnaires that were distributed to pre-service teachers, 49 were returned, a return rate of $82 \%$ and out of the 70 questionnaires that were distributed to in-service teachers, 47 were returned, a return rate of $67 \%$. The final sample that was used for the study consisted of 96 pre-service and in-service teachers.

Instrument: The questionnaire was self-designed based on NCTM competencies in 1991. The questionnaire consisted of 24 items using a five-point Likert scale ranging from strongly disagree to strongly agree. The questionnaire was given to three specialists in the special education department and two specialists in the Curriculum and Instruction Department (Mathematics Education) for review and to check validity and reliability.

The instruments addressed the five standards that were released by the National Council of Teachers of Mathematics (1991). The first standard consisted of four competencies; the second standard consisted of four competencies; the third standard consisted of three competencies; the fourth standard consisted of eight competencies, and the fifth standard consisted of five competencies.

\subsection{Reliability Analysis}

Cronbach Alpha was used to evaluate the reliability of the domains of the questionnaire.

Table-1. Reliability Coefficient for the five standards.

\begin{tabular}{l|c}
\hline Standard & Alpha \\
\hline 1. Experiencing Good Mathematics Teaching. & 0.66 \\
\hline 2. Knowing Mathematics and School Mathematics. & 0.79 \\
\hline 3. Knowing Students as Learners of Mathematics. & 0.66 \\
\hline 4. Knowing Mathematical Pedagogy. & 0.89 \\
\hline 5. Developing as a Teacher of Mathematics. & 0.80 \\
\hline Total & 0.94 \\
\hline
\end{tabular}

Table 1 shows that the domain, Experiencing Good Mathematics Teaching yielded a reliability coefficient of .66; the domain Knowing Mathematics and School Mathematics yielded a reliability coefficient of .79; the domain Knowing Students as Learners of Mathematics yielded a reliability coefficient of .66; the domain Knowing Mathematical Pedagogy yielded a reliability coefficient of .89 and the domain Developing as a Teacher of Mathematics yielded in a reliability coefficient of .80, all of which are appropriate for the purpose of the study.

Validity: The questionnaire was given to five faculty members in the Special Education Department at one of the universities to make sure that the Arabic version was similar to the English version. The questionnaire was also 
given to six specialists in Mathematics Education for review. Their feedback was taken into consideration, and several questions were omitted from the instrument, and several questions were reworded for clarity.

\section{RESULTS}

The purpose of the current study was to find out whether special education pre-service and in-service teachers were aware of NCTM standards since it is a prediction of the success of teaching students with learning disabilities.

Table-2. Means, standard deviations and t-test of pre-service and in-service teachers.

\begin{tabular}{|c|c|c|c|c|c|c|c|c|}
\hline \multirow[t]{2}{*}{ Area } & \multicolumn{2}{|c|}{ Pre-service } & \multicolumn{2}{|c|}{ In-service } & \multirow[t]{2}{*}{ f } & \multirow[t]{2}{*}{ DF } & \multirow[t]{2}{*}{$\mathbf{t}$} & \multirow[t]{2}{*}{ Sig. } \\
\hline & Mean & SD & Mean & SD & & & & \\
\hline 1. Experiencing Good Mathematics Teaching. & 2.42 & 0.80 & 3.47 & 0.52 & 6.46 & 94 & 7.63 & 0.013 \\
\hline 2. Knowing Mathematics and School Mathematics. & 2.12 & 0.76 & 3.73 & 0.54 & 0.67 & 94 & 11.96 & 0.417 \\
\hline 3. Knowing Students as Learners of Mathematics. & 2.42 & 0.95 & 3.52 & 0.74 & 3.82 & 94 & 6.30 & 0.054 \\
\hline 4. Knowing Mathematical Pedagogy. & 2.32 & 0.64 & 3.86 & 0.50 & 0.15 & 94 & 13.06 & 0.147 \\
\hline 5. Developing as a Teacher of Mathematics. & 2.22 & 0.69 & 3.87 & 0.38 & 7.91 & 94 & 14.45 & 0.006 \\
\hline Total & 2.30 & 0.61 & 3.69 & 0.19 & 34.41 & 94 & 14.85 & 0.000 \\
\hline
\end{tabular}

Table 2 shows that the mean of pre-service teachers on the first standard of experiencing good mathematics teaching was $2.42(\mathrm{SD}=.80)$. However, in-service teachers had a mean of $3.47(\mathrm{SD}=.52)$ on the same standard. The mean of pre-service teachers on standard 2, knowing mathematics and school mathematics, was 2.12 (SD = $.76)$, whereas the mean was $3.73(\mathrm{SD}=.54)$ for in-service teachers on the same standard. Regarding standard 3, knowing students as learners of mathematics, the mean for pre-service teachers was $2.42(\mathrm{SD}=.95)$, and for inservice teachers, the mean was $3.52(\mathrm{SD}=.74)$. The mean of pre-service teachers on the fourth standard, developing as a teacher of mathematics, was $2.22(\mathrm{SD}=.69)$, and for in-service teachers, the mean was $3.87(\mathrm{SD}=.38)$. The overall mean of pre-service teachers on all five standards was $2.30(\mathrm{SD}=.61)$, and for in-service teachers, it was $3.69(\mathrm{SD}=.19)$. Table 2 indicates that in-service teachers are higher in their competencies of NCTM standards than pre-service teachers.

To statistically check whether there was a significant difference between pre-service teachers and in-service teachers, the independent t-test procedure was used, and the result (Table 2 ) indicated a significant difference between pre-service teachers and in-service teachers experiencing good mathematics teaching $(t=7.63, f=646$, $d f$ $=94, \underline{p}>.05)$, and in the area of developing as a teacher of mathematics $(t=14.45, \mathrm{f}=7.91, \mathrm{df}=94, \underline{\mathrm{p}}>.01)$. Whereas no significant difference was found in the area of knowing mathematics and school mathematics $(t=11.96$, $\mathrm{f}=.67 \mathrm{df}=94, \mathrm{p}<.05)$, the area of knowing students as learners of mathematics $(\mathrm{t}=6.30, \mathrm{f}=3.82 \mathrm{df}=94, \mathrm{p}<$ $.01)$, and the area of knowing mathematics pedagogy $(t=13.06, f=2.13, \mathrm{df}=94, \mathrm{p}<.05)$. A significant difference is also found between pre-service and in-service teachers on their response to the 5 standards all together $(\mathrm{t}=14.85, \mathrm{f}$ $=34.41, \mathrm{df}=94, \mathrm{p}>.01)$.

\section{DISCUSSION}

As discussed earlier, teaching mathematics is a complex and challenging task, even in typical situations. When it comes to teaching students with disabilities, the task becomes even harder and more complicated, which calls for teachers who are well prepared and have the necessary competencies to educate such students.

By examining the results of the current study, it is evident that there is a lack of preparation for future special education teachers who are expected to teach students with mathematical learning disabilities. The responses of pre-service special education teachers on the items of the first standard "Experiencing Good Mathematics Teaching" show that they had not been exposed to good teaching of mathematics. This is not surprising since mathematic courses are offered in the department of mathematics in the college of science, where teaching is still being practiced traditionally (e.g., lecture, and presentation...etc) without consideration for students from the College of Education who are taking the course alongside students from the College of Science. 
On the other hand, responses of in-service teachers on same standards show that they are exposed to good teaching of mathematics. This is not surprising since in-service teachers gain experience in teaching by practicing and since they are employed as teachers they must have learnt the strategies in which they can deliver good teaching to their students; in addition, they might have experienced lots of professional development throughout their years of teaching and this would also add to their skills of being good mathematic teachers.

The second standard," Knowing Mathematics and School Mathematics," was not accomplished either. This could be because the content of the mathematical courses that students took did not match this standard, or that mathematic courses do not concentrate on such issues. NCTM standards are not integrated within the curriculum at the pre-service level. Also, the curriculum that concentrates on methods of teaching mathematics is at the least level, students take only a maximum of two courses that include methods of teaching mathematics and the strategies discussed in such courses are general methods of teaching rather than being based on NCTM standards. However, in-service teachers were competent in the items on the second standard. Again, in-service teachers gain the knowledge of NCTM standards by practice and professional development during their work as teachers. The Ministry of Education in the last few years began to concentrate of enhancing the level of teaching for those who are already working in the field and the professional development programs they provide are based on international standards, therefore is expected that in-service teachers learn about NCTM standards and reflect them in their teaching.

The third standard," Knowing Students as Learners of Mathematics," was not accomplished either. The items that were asked under this standard were mainly designed for special education teachers (e.g., I have learned how to recognize the exceptional performance of my students and how to adapt methods to meet their needs). Nevertheless, pre-service teachers indicated that they had not learned such competencies in their program even though it is an essential component of the instructional strategies course in special education. This could be because students themselves are weak in mathematics, and therefore they did not understand what was being taught, or the professor who taught them the course did not concentrate on the chapter that discusses this component. In-service teachers, on the other hand, were competent in this standard, most likely due to their experiences in dealing with students suffering from learning disabilities in mathematics; another reason could be that the Ministry of Education provides its teachers with workshops that concentrate on the most recent evidence-based strategies and best practices in the field of mathematics and especially teaching mathematics in inclusive classrooms.

The fourth standard, "Knowing Mathematical Pedagogy," was not accomplished. This could be due to the fact that there are none or few courses in the college that address mathematical pedagogy. Even when pre-service teachers take courses that concentrate on pedagogy, they are not focused on mathematics pedagogy rather they take general pedagogy skills without knowing the source of such skills and weather they are in line with international pedagogy methods that are derived from reputable standards. In-service teachers indicated competency concerning this standard as well. Again, insrvice teachers and because of their experience and being exposed to many workshops and seminars during their course of teaching, they become aware of methods of teaching that are essential part of being an effective teacher, in addition the workshops they attend are well constructed and indicate the sources from which those methods were derived.

The fifth standard, "Developing as a Teacher of Mathematics," was not accomplished either. This could be due to the fact that pre-service special education teachers hardly ever attend workshops, seminars, or take additional courses in mathematics. In-service teachers, however, were competent in this standard. As previously discussed, the different results between in-service and pre-service teachers are mostly due to the extensive training that in-service teachers receive during their employment as teachers. Nonetheless, teacher education programs do not provide preservice teachers with the needed training, pedagogical knowledge, and content knowledge needed to provide high quality mathematics instruction to students with disabilities. 
The results of the current study indicate that pre-service special education has not accomplished any of the professional development standards set by National Council of Teachers of Mathematics (1991). This indicates that students who have mathematical learning disabilities will be taught by teachers who are not qualified to teach them mathematics, which will result in the failure of trying to move those children from special education classrooms back into the regular education classroom. The requirements for graduating as a special education teacher in any Universities do not include in many cases extensive course work in content areas in special education (i.e. Methods of Teaching Mathematics) and thus students graduate without having any course work related to mathematics. However, it seems that once teachers are in the field, they gain experience in mathematics. It is important to note here that all in-service teachers who participated in the current study have had more than five years of teaching experience, and they have all attended more than six training programs (e.g., workshops, seminars, lectures...etc).

\section{LIMITATIONS}

Even though important and useful results are derived from the current study, yet it would be insufficient to generalize the results to places other than where the study took place. This is mainly because universities in the region have different teacher education program structure, and also the sample of the study is considered small if compared to students in other universities. Therefore, future studies should take into consideration larger samples and from several universities in the region. Also, the in-service teachers sample should be larger and should take into consideration teachers with varying years of experience and different training programs that those teachers have undertaken.

\section{IMPLICATIONS FOR PRACTICE}

Special Education programs should take into consideration NCTM standards to prepare qualified teachers who can work effectively with students with mathematical learning disabilities. It is further recommended that more studies are conducted on larger samples of pre-service and in-service special education teachers, in order to determine their competencies and ability to teach students with mathematical learning disabilities.

Intensive training should be the goal of teacher education programs to better train pre-service teachers to educate students with learning disabilities.

Funding: This study received no specific financial support.

Competing Interests: The authors declare that they have no competing interests.

Acknowledgement: Both authors contributed equally to the conception and design of the study.

\section{REFERENCES}

Badian, N. A. (1983). Dyscalculia and non-verbal disorders of learning. In H. R. Myklebust (Ed.), Progress in learning disabilities (Vol. 5, pp. 235-264). New York: Grune \& Stratton.

Bley, N. S., \& Thornton, C. A. (1995). Teaching mathematics to students with learning disabilities. Austin, TX: PRO-ED, Inc.

Boston, M. D., \& Smith, M. S. (2009). Transforming secondary mathematics teaching: Increasing the cognitive demands of instructional tasks used in teachers' classrooms. Journal for Research in Mathematics Education, 40(2), 119-156.

Brian, T., Bay, M., Lopez-Reyna, N., \& Donahue, M. (1991). Characteristics of students with learning disabilities: A summary of the extant data base and its implications for educational programs. In J. W. Lloyd, N. Nirbhay, \& A. C. Repp (Eds.), The Regular Education Initiative: Alternative perspectives on concepts, issues, and models (pp. 113-131). Sycamore, IL: Sycamore.

Cawley, J. F., Baker-Kroczynski, S., \& Urban, A. (1992). Seeking excellence in mathematics education for students with mild disabilities. Teaching Exceptional Children, 24(2), 40-43. Available at: https://doi.org/10.1177/004005999202400209. 
Cawley, J. F., \& Parmar, R. S. (1992). Arithmetic programming for students with disabilities: An alternative. Remedial and Special Education, 13(3), 6-18. Available at: https://doi.org/10.1177/074193259201300302.

Cawley, J. F., \& Miller, J. H. (1989). Cross-sectional comparisons of the mathematical performance of children with learning disabilities: Are we on the right track toward comprehensive programming? Journal of Learning Disabilities, 22(4), 250254. Available at: https://doi.org/10.1177/002221948902200409.

Desoete, A. (2007). Students with mathematical disabilities in Belgium: From definition, classification and assessment to STICORDI devices. In Advances in Learning and 16 Behavioral Disabilities, ed. T.E. Scruggs and M.A. Mastropieri (pp. 181-222). Amsterdam and Oxford: Elsevier Press.

Englert, C. S., Culatta, B. E., \& Horn, D. G. (1987). Influence of irrelevant information in addition word problems on problem solving. Learning Disability Quarterly, 1O(1), 29-36. Available at: https://doi.org/10.2307/1510752.

Fuchs, L. S., Fuchs, D., Hamlett, C. L., \& Appleton, A. C. (2002). Explicitly teaching for transfer: Effects on the mathematical problem-solving performance of students with mathematics disabilities. Learning Disabilities Research \& Practice, 17(2), 90-106. Available at: https://doi.org/10.1111/1540-5826.00036.

Garnett, K., \& Fleischner, J. E. (1983). Automatization and basic fact performance of normal and learning disabled children. Learning Disability Quarterly, 6(2), 223-230.

Garnett., K. (1987). Math learning disabilities: Teaching and learners. Reading, Writing, and Learning Disabilities, 3(1), 1-8.

Geary, D. C. (1993). Mathematical disabilities: Cognitive, neuropsychological, and genetic components. Psychological Bulletin, $114(2), 345-362$.

Geary, D. C. (2004). Mathematics and learning disabilities. Journal of Learning Disabilities, 37(1), 4-15.

Geary., D. C. (1990). A componential analysis of an early learning deficit in mathematics. Journal of Experimental Child Psychology, 49(3), 363-383.

Goldman, S. R., Pellegrino, J. W., \& Mertz, D. L. (1988). Extended practice of basic addition facts: Strategy changes in learningdisabled students. Cognition and Instruction, 5(3), 223-265. Available at: https://doi.org/10.1207/s1532690xci0503_2.

Graves, A., Landers, M. F., Lokerson, J., Luchow, J., \& Horvath, M. (1993). The development of a competency list for teachers of students with learning disabilities. Learning Disabilities Research \& Practice, 8, 188-199.

Graves, A., Landers, M. F., Lokerson, J., Luchow, J., Horvath, M., \& Garnett, K. (1992). The DLD competencies for teachers of students with learning disabilities. Reston, VA: Division for Learning Disabilities, Council for Exceptional Children.

Jimenez, B. A., \& Stanger, C. (2017). Math manipulatives for students with severe intellectual disability: A survey of special education teachers. Research, Advocacy, and Practice: For complex and Chronic Conditions: A Journal for Physical, Health, and Multiple Disabilities, 36(1), 1-12. Available at: https://doi.org/10.14434/pders.v36i1.22172.

Jordan, N. C., Glutting, J., \& Ramineni, C. (2010). The importance of number sense to mathematics achievement in first and third grades. Learning and Individual Differences, 2O(2), 82-88. Available at: https://doi.org/10.1016/j.lindif.2009.07.004.

Kelly, B., Gersten, R., \& Carnine, D. (1990). Student error patterns as a function of curriculum design: Teaching fractions to remedial high school students and high school students with learning disabilities. Journal of Learning Disabilities, 23(1), 23-29. Available at: https://doi.org/10.1177/002221949002300108.

Lee, A., Browder, D. M., Flowers, C., \& Wakeman, S. (2016). Teacher evaluation of resources designed for adapting mathematics for students with significant cognitive disabilities. Research and Practice for Persons with Severe Disabilities, 41(2), 132137. Available at: https://doi.org/10.1177/1540796916634099.

Lyons, I. M., \& Beilock, S. L. (2011). Numerical ordering ability mediates the relation between number-sense and arithmetic competence. Cognition, 121, 256-261. Available at: 10.1016/j. cognition.2011.07.009.

McLeod, T. M., \& Armstrong, S. W. (1982). Learning disabilities in mathematics-skill deficits and remedial approaches at the intermediate and secondary level. Learning Disability Quarterly, 5(3), 305-311. Available at: https://doi.org/10.2307/1510297.

Mercer, C. D., \& Miller, S. P. (1992). Teaching students with learning problems in math to acquire, understand, and apply basic math facts. Remedial and Special Education, 13(3), 19-35. Available at: https://doi.org/10.1 177/074193259201300303. 
Montague, M., \& Applegate, B. (1993). Middle school students' mathematical problem solving: An analysis of think-aloud protocols. Learning Disability Quarterly, 16(1), 19-32. Available at: https://doi.org/10.2307/1511157.

Montague, M., \& Bos, C. S. (1986). The effect of cognitive strategy training on verbal math problem solving performance of learning disabled adolescents. Journal of Learning Disabilities, 19(1), 26-33.

National Council of Teachers of Mathematics. (1991). Professional standards for teaching mathematics. Reston, VA: Author.

National Council of Teachers of Mathematics (NCTM). (2007). Mathematics teaching today: Improving practice, improving student learning.

Parmar, R. S. (1992). Protocol analysis of strategies used by students with mild disabilities when solving arithmetic word problems. Diagnostique, 17(4), 227-243.

Parmar, R. S., Cawley, J. F., \& Frazita, R. R. (1996). Word problem-solving by students with and without mild disabilities. Exceptional Children, 62(5), 415-429.

Rivera, D. M., \& Smith, D. D. (1987). Influence of modeling on acquisition and generalization of computational skills: A summary of research findings from three sites. Learning Disability Quarterly, 10(1), 69-80. Available at: https://doi.org/10.2307/1510756.

Scheid, K. (1990). Cognitive-based methods for teaching mathematics to students with learning problems. Columbus, OH: Information Center for Special Education Media and Materials.

Sheppard, M. E., \& Wieman, R. (2020). What do teachers need? Math and special education teacher educators' perceptions of essential teacher knowledge and experience. The Journal of Mathematical Behavior, 59, 100798. Available at: https://doi.org/10.1016/j.jmathb.2020.100798.

Spooner, F., Root, J. R., Saunders, A. F., \& Browder, D. M. (2019). An updated evidence-based practice review on teaching mathematics to students with moderate and severe developmental disabilities. Remedial and Special Education, 4O(3), 150-165. Available at: https://doi.org/10.1177/0741932517751055.

Stock, P., Desoete, A., \& Roeyers, H. (2006). Focussing on mathematical disabilities: a search for definition, classisfication and assessment. In Learning Disabilities. New Research, ed. S. V. Randall (pp. 29-62). Hauppage, NY: Nova Science.

Van Steenbrugge, H., Valcke, M., \& Desoete, A. (2010). Mathematics learning difficulties in primary education: Teachers' professional knowledge and the use of commercially available learning packages. Educational Studies, 36(1), 59-71. Available at: https://doi.org/10.1080/03055690903148639.

Wagner, M. (1990). The school programs and school performance of secondary students classified as learning disabled: Findings from the national longitudinal transition study of special education students. Menlo Park, CA: SRI International.

Woodward, J. (1991). Procedural knowledge in mathematics: The role of the curriculum. Journal of Learning Disabilities, 24(4), 242-251. Available at: https://doi.org/10.1177/00222 1949102400408.

Views and opinions expressed in this article are the views and opinions of the author(s), International Journal of Education and Practice shall not be responsible or answerable for any loss, damage or liability etc. caused in relation to/arising out of the use of the content. 